\title{
The Effects of Parent Management Training, Problem-solving Skills Training and the Eclectic Training on Conduct Disorder in Iranian Elementary School Students
}

\author{
Mohsen Lali ${ }^{1}$, Mokhtar Malekpour ${ }^{1}$, Hossien Molavi ${ }^{1}$, Ahmad Abedi ${ }^{1}$ \& Karim Asgari ${ }^{1}$ \\ ${ }^{1}$ Faculty of Psychology and Education, University of Isfahan, Iran \\ Correspondence: Mohsen Lali, Faculty of Psychology and Education, University of Isfahan, Isfahan 8174673441, \\ Iran. Tel: 98-913-319-6760. E-mail: m.dastgerdy70@yahoo.com
}

Received: January 24, 2012

Accepted: February 6, 2012 Published: June 1, 2012

doi:10.5539/ijps.v4n2p154

URL: http://dx.doi.org/10.5539/ijps.v4n2p154

\begin{abstract}
The present study investigated the effects of parent management training, problem-solving skills training and the eclectic training on symptoms of conduct disorder in Isfahan elementary school students during the educational year 2010-2011. The sample included 40 male pupils (ages 10 to 11) randomly selected assigned to experimental and control groups. Four groups were formed (each group consisted of 10 students), namely parent management training, problem-solving skills training, eclectic training and a control group. Child Behavior Checklist (CBCL, Achenbach, 1991) and clinical interview were used as research instruments. Three methods were used as intervention (parent management training, problem-solving skills training and the eclectic training).The results of the analysis of covariance ANCOVA with repeated measure indicated a significant difference between parent management training, eclectic training and the control group, however no significant difference was observed between problem solving skills training group and the other groups. Scheffe post-hoc test was also used which indicated that parent management training and eclectic training intervention decreased the conduct disorder symptoms in comparison with the control group. Also, the results indicated that eclectic training was more effective than parent management training.
\end{abstract}

Keywords: parent management training, problem-solving skills training, eclectic training, conduct disorder

\section{Introduction}

Psychological problems that commonly begin during childhood are listed in the DSM-IV-TR category disorders usually first diagnosed in infancy, childhood, or adolescence. (Oltmanns \& Emery, 2012). One of the most important disorders in this category is the various externalizing disorders. Externalizing disorders are the most commonly diagnosed childhood disorders and account for about half of all children in treatment (Kazdin, 1995).These disorders create difficulties for the child's external world. They are characterized by children's failure to control their behavior according to the expectations of parents, peers, teachers, and/or legal authorities. (Oltmanns \& Emery, 2012).Conduct disorder (CD) represents one of the forms of externalizing disorder in child and adolescent psychiatry. According to DSM-IV-TR, the essential feature of this is a repetitive and persistent pattern of behavior in which the basic rights of others, or major age-appropriate societal norms, are violated (APA, 2003). These traits reflect an affective and interpersonal style of the individual (e.g., lack of empathy, lack of guilt, shallow emotions, egocentricity ,callous use of others for own gain)and seem to be associated with a more severe, violent and chronic pattern of antisocial behavior (Scheepers, Buitelaar \& Matthys, 2011).

DSM-IV-TR classified CD into childhood-onset, compared with adolescent-onset types. Conduct disorder, childhood-onset type includes onset of at least one criterion characteristic of conduct disorder prior to age10years (Moffitt, 1993). Conduct disorder, adolescent-onset type is absence of any criteria characteristic of conduct disorder prior to age 10 years. (Frick \& Dickens, 2006). The estimated numbers of people who suffer from conduct disorders depend on the diagnostic criteria of the time. General population estimates varies from 1 to $10 \%$ (APA, 2003). In relation to gender, differences in the prevalence of conduct disorder is found in most studies, with some reporting a4to1 ratio of boys over girls (Lahey, Miller, Gordon \& Riley, 1999).

A variety of etiologies has been suggested for the development of $\mathrm{CD}$, but, in truth, there are likely a number of different pathways that lead to the various behavioral problems associated with this diagnosis. According to 
Schroeder \& Gordon (2002), "these pathways typically involve some combination of genetic or biologically based child characteristics or predispositions, parenting dysfunction, and environmental or contextual circumstances" (p. 341). The consequences of this disorder are aggression, substance abuse, family and job problems. These children and adolescents tend to have negative long-term outcomes as adults, with about $80 \%$ of them likely to meet criteria for a psychiatric disorder (Kazdin, 2003). Research suggests that one of the worst and the most important consequences of conduct disorder in adulthood is antisocial personality disorder (Lahey, Moffitt \& Caspi, 2003).

Treating children and adolescents who suffer from CD is a difficult task due to the complexity of factors associated with this particular disorder (Frick, 1998, $2001 \&$ Kazdin, 1995). A variety of treatments have been applied to children and adolescents with CD. However, only a small number of treatments have been shown to reduce $\mathrm{CD}$ behaviors. Treatment procedures tend to be most effective when the child is young (under 8 years of age) and early in the development of problem behaviors (Frick, 1998; Kazdin 1996; McMahon \& Wells, 1998). In recent years, despite medical treatment, psychological approaches and interventions in the treatment of conduct disorder has been found. These treatment approaches include cognitive and social skills interventions and treatments which are based on the family. According to Kazdin (2001), "one of the most well investigated and well established of the therapeutic approaches for behavior problems is parent management training" (p. 408). The parent management training sometimes called parent skills training, was developed out of the social learning theory, in an effort to intervene in the coercive cycle between parent and child.The fundamental focus of this approach is to teach parents how to develop and employ contingency management programs at home. Parent management training(PMT)concentrates on improving the quality of parent-child relationships, for example, having parents more involved with child's daily activities and increasing communication and parental responsiveness, improving the communicating of clear and explicit rules and expectations, improving parents' ability to supervise their children's behavior, and teaching parents more effective and consistent disciplining styles (Ollendick \& King, 2000). The main goal of parent management training, is to change the pattern of interaction between parent - child to develop socially desirable behaviors and avoid violence in the family (Mabe, 2003).In this method parents are taught to increase prosocial and reduce problem behaviors via social-learning strategies such as monitoring and reinforcement(Sanders, Bor \& Morawska, 2007). The core treatment is 12 sessions, each session lasting between 45 and 60 minutes. Between sessions, the therapist calls the parents to provide support for the practicing of parenting skills at home.

Another therapeutic approach for conduct disorder is problem-solving skills training (PSST). This method is one of the most extensively researched cognitive- behavioral treatments for antisocial behavior in childhood (Kazdin, Esveldt-Dawson, French \& Unis, 1987). In PSST, children are seen individually to learn problem-solving skills (e.g., generating alternative solutions, means-ends thinking) to utilize in interpersonal interactions(e.g., with parents, teachers, siblings, and peers). Kazdin (2003) believes, "that teaching problem solving skills can be effective in reducing aggression in hospitalized patients and outpatient conduct disorder"(p.241).The program itself focuses on teaching and reinforcing prosocial problem solving skills among children with disruptive behavior disorders in order to promote their ability to effectively manage potentially volatile interpersonal situations. Within the sessions, participants learn problem solving skill training through practice, modeling, role-playing, corrective feedback, and social and token reinforcement (Nock, Ferriter \& Holmberg, 2007).

Parent management training and problem-solving skills training were used for parents and their children in this study. The combination of these two methods (PMT and PSST) is very effective for treatment of conduct disorder (kazdin, 1997). Therefore, in addition to these methods eclectic approach was also used. In this approach parent management training and problem-solving skills training are used for parents and their children.

Previous research showed that parent management training and problem-solving skills training are effective in conduct disorder. It also seems necessary to study the effectiveness of these methods more carefully in countries with diverse cultures and family structures. Therefore, the aim of the present study is to assess the impact of parent management training, problem-solving skills training and the eclectic training on symptoms of conduct disorder in Iran. Based on the research purpose, three causal hypotheses were suggested:

1) Parent management training decreases conduct disorder symptoms.

2) Problem-solving skills training decreases conduct disorder symptoms.

3) Eclectic training decreases conduct disorder symptoms. 


\section{Methodology}

\subsection{Instruments}

Instruments used in this research included Child Behavior Checklist (CBCL), Structural Clinical Interview for DSM-IV.T-R and a questionnaire for parents' demographic specifications.

\subsubsection{Child Behavior Checklist (CBCL)}

Child Behavior Checklist and Teacher Report Form by caretaker and school teacher, respectively, provide a dimensional assessment across an array of behavioral and emotional problems and social competencies. This instrument can either be self-administered or administered through an interview. The CBCL is a behavioral checklist completed by a parent, teacher or a primary caregiver. It provides information as to a child's competencies and behavior (Achenbach, 1991). Parents and teachers are asked to rate the frequency of 112 items from 0 (not true of the child), 1 (somewhat or sometimes true), or 2 (very true or often true). The CBCL manual reports item reliabilities greater than 0.90 between mothers' reports, mothers' and fathers' reports, and reports from three different interviewers. Several studies support the construct validity of the CBCL, such as studies comparing "normal" children with children referred to a clinic. The discriminative power of the test is fairly high (Domino \& Domino, 2006). In this study, the Cronbach's alpha reliability coefficient was 0.91 .

\subsubsection{Structural Clinical Interview for DSM-IV.T-R}

Clinical interview is one of the most important diagnostic tools for conduct disorder. This method provided the opportunity to collect information on conduct disorder and symptoms, including the context in which these occur, their onset, frequency, severity, and impact on functioning.

\subsubsection{Questionnaire for Parents' Demographic Specifications}

This questionnaire includes questions such as family socio-economic level, Parents' education, parents' profession.

\subsection{Participants}

Participants were 40 male students with their parents. These children were between10-11 years old, with a mean age of 10.64 years $(\mathrm{SD}=0.86)$. The subjects consisted of four groups of male students in fourth and fifth grades diagnosed with conduct disorder during the educational year 2010-2011. Characteristics of the groups are shown in Tables 1, 2 and 3. Table 1 shows the family socio-economic level; table 2 shows the parents' education and table 3 shows the parental employment.

Table 1. Family socio-economic level

\begin{tabular}{cccccc}
\hline $\begin{array}{c}\text { Socioeconomic } \\
\text { level }\end{array}$ & PMT & PSST & PMT \& PSST & CONTROL & Total \\
\hline low & 5 & 5 & 4 & 3 & 17 \\
Medium & 3 & 4 & 5 & 4 & 16 \\
High & 2 & 1 & 1 & 3 & 7 \\
Total & 10 & 10 & 10 & 10 & 40 \\
\hline
\end{tabular}

Table 2a. Father's education

\begin{tabular}{cccccc}
\hline Group & \multicolumn{5}{c}{ Students Father's education } \\
& $\begin{array}{c}\text { Elementary } \\
\text { School }\end{array}$ & $\begin{array}{c}\text { High School } \\
\text { drop-out }\end{array}$ & $\begin{array}{c}\text { High School } \\
\text { Diploma }\end{array}$ & Post Diploma & Total \\
\hline PMT \& PSST & 3 & 5 & 1 & 1 & 10 \\
PMT & 4 & 4 & 2 & 0 & 10 \\
PSST & 4 & 3 & 2 & 1 & 10 \\
CONTROL & 3 & 5 & 2 & 0 & 10 \\
Total & 14 & 17 & 7 & 2 & 40 \\
\hline
\end{tabular}


Table 2b. Mother's education

\begin{tabular}{cccccc}
\hline Group & \multicolumn{5}{c}{ Students Mother's education } \\
& $\begin{array}{c}\text { Elementary } \\
\text { School }\end{array}$ & $\begin{array}{c}\text { High School } \\
\text { drop-out }\end{array}$ & $\begin{array}{c}\text { High School } \\
\text { Diploma }\end{array}$ & Post Diploma & Total \\
\hline PMT \& PSST & 2 & 4 & 3 & 1 & 10 \\
PMT & 3 & 5 & 2 & 0 & 10 \\
PSST & 4 & 3 & 2 & 1 & 10 \\
CONTROL & 3 & 3 & 3 & 1 & 10 \\
Total & 12 & 15 & 10 & 3 & 40 \\
\hline
\end{tabular}

Table 3. Parental employment

\begin{tabular}{ccccc}
\hline Group & \multicolumn{2}{c}{$\begin{array}{c}\text { Students Father's Occupation } \\
\text { Employed }\end{array}$} & Unemployed & \multicolumn{2}{c}{$\begin{array}{c}\text { Students Mother's Occupation } \\
\text { Employed }\end{array}$} & \begin{tabular}{c} 
Unemployed \\
\hline PMT \& PSST
\end{tabular} & 9 & 1 & 1 & 9 \\
PMT & 10 & 0 & 2 & 8 \\
PSST & 9 & 1 & 0 & 10 \\
CONTROL & 9 & 1 & 0 & 10 \\
Total & 37 & 3 & 3 & 37 \\
\hline
\end{tabular}

\subsection{Procedure}

The study was an experimental one with a pre-test, post-test and a 4-month follow-up design which involved 3 experimental and 1 control group. The necessary criteria for present research were being male, being 10-11 years old, primary diagnosis of conduct disorder according to diagnostic criteria of DSM-IV-TR, and Child Behavior Checklist (CBCL, Achenbach, 1991), no regular use of psychiatric drugs, not having other treatments, not having physical problems and not participating simultaneously in other clinical programs during this research. 10 elementary schools were randomly selected from five areas of Isfahan and then divided in to 4 groups. Sampling was multistage cluster sampling. Then Child Behavior Checklist (CBCL, Achenbach, 1991) the pre-2001 version for ages 4-18 was used. Subjects were put in to the experimental and control groups through random selection. From this sample, 10 subjects were placed in each of parent management training, problem-solving skills training and the eclectic training groups. In order to reach a definitive diagnosis of conduct disorder, the children were interviewed by a psychiatrist and a clinical psychologist. Kappa $(\kappa)$ coefficient (Cohen, 1960) was calculated to determine the inter-rater reliability of the clinical interviews. The coefficient of agreement between interviewers was 0.76 . After obtaining informed consent from parents, intervention was made. 12 weekly parent management training sessions were held for two months (one-hour a week) for parents (mothers and fathers).The children participated in 8 weekly problem-solving skills training sessions (1-hour a week) too. Treatment was conducted by trained professionals in the psychological services and counseling center.

\section{Results}

The obtained data were evaluated by using SPSS 16.00 (Statistical Package for Social Sciences). Mean and standard deviation were used as descriptive analysis. Group comparisons were made with analysis of covariance (ANCOVA).When a significant difference was detected between groups, Scheffe post-hoc analysis was used for multiple comparisons.

Table 4 shows the mean and standard deviation scores for pre-test, post-test and follow-up of the four groups used in the study. 
Table 4. Summary of the descriptive data (means and standard deviations) of four groups

\begin{tabular}{ccccccccc}
\hline & \multicolumn{2}{c}{ PMT } & \multicolumn{2}{c}{ PSST } & \multicolumn{2}{c}{ PMT\&PSST } & \multicolumn{2}{c}{ CONTROL } \\
\hline Stage & M & SD & M & SD & M & SD & M & SD \\
Pre-Test & 74.7 & 5.7 & 73.4 & 2.4 & 76.6 & 8.3 & 72.9 & 3.9 \\
Post-Test & 55.9 & 2.1 & 68.9 & 3 & 52.1 & 2.2 & 72.9 & 2.7 \\
Follow-up & 57.8 & 2.2 & 68.5 & 1.9 & 54.8 & 3.3 & 69.6 & 2.9 \\
\hline
\end{tabular}

As it is shown in table 4, the means on the post-test and the follow-up of the parent management training and the eclectic training were less than that of the problem-solving skills training and the control groups.

As table 5 shows omitting the pre-test effect lead to a significant difference between groups in post-test means [F $=29.91, \mathrm{P}<0.001]$. It was also observed that the means of post-test of the experimental groups (parent management training and eclectic training) were significantly lower than that of the control group. Therefore the conduct symptoms in the experimental groups decreased in comparison with the control group in post experiment stage.

Table 5. ANCOVA for post-test means of conduct disorder symptoms after controlling for the pretest

\begin{tabular}{llllllll}
\hline Resource & SS & df & MS & F & Sig & $\begin{array}{l}\text { Partial } \\
\text { Eta }\end{array}$ & $\begin{array}{l}\text { Observed } \\
\text { power }\end{array}$ \\
\hline pre-test & 70.81 & 1 & 70.81 & 29.37 & 0.00 & 0.928 & 1.000 \\
groups & 216.36 & 3 & 72.12 & 29.91 & 0.001 & 0.925 & 1.000 \\
error & 84.35 & 35 & 2.41 & & & & \\
total & 3210 & 40 & & & & & \\
\hline
\end{tabular}

According to Table 6, there was a significant difference between groups in follow-up means of conduct disorder scores after controlling the pre-test effect $[\mathrm{F}=28.7, \mathrm{P}<0.001]$. Therefore, the conduct disorder scores in experimental group in follow-up stage decreased in comparison with the control group.

Table 6. ANCOVA for comparing means of conduct disorder symptoms follow- up after controlling pretest

\begin{tabular}{llllllll}
\hline Resource & SS & Df & MS & F & Sig & Partial Eta & $\begin{array}{l}\text { Observed } \\
\text { power }\end{array}$ \\
\hline pre-test & 39.75 & 1 & 39.75 & 8.92 & 0.005 & 0.83 & 1.000 \\
groups & 375.24 & 3 & 125.08 & 28.07 & 0.001 & 0.87 & 1.000 \\
error & 155.94 & 3 & 4.41 & & & & \\
total & 3849 & 40 & & & & & \\
\hline
\end{tabular}

When a significant difference was detected between the groups, Scheffe post-hoc test analysis was used for multiple comparisons. The result of multiple comparison output for the conduct disorder data is shown in table4.

As it is shown in Table 7, the multiple comparisons indicated a significant difference between the parent management training and the control group $(\mathrm{P}<.01)$, the eclectic training and the control group $(\mathrm{P}<.003)$. However there was no significant difference between the problem solving skills training and the control group $(\mathrm{P}<$.093). 
Table 7. Multiple comparisons

\begin{tabular}{cccc}
\hline \multirow{2}{*}{ (I)group } & (J)group & $\begin{array}{c}\text { Mean Difference } \\
(\mathrm{I}-\mathrm{J})\end{array}$ & Sig. \\
\hline \multirow{2}{*}{ PMT } & PSST & -4.3000 & 0.049 \\
& PMT \& PSST & -12.333 & 0.96 \\
& CONTOROL & -17.3667 & 0.01 \\
\multirow{2}{*}{ PSST } & PMT & 12.3000 & 0.049 \\
& PMT \& PSST & 16.9 & 0.001 \\
& CONTOROL & -4.3 & 0.093 \\
PMT\&PSST & PMT & -4.007 & 0.96 \\
& PSST & -16.9333 & 0.001 \\
& CONTOROL & -2.6667 & 0.003 \\
CONTOROL & PMT & 21.33 & 0.001 \\
& PSST & 17.23 & 0.93 \\
& PMT \&PSST & 4.6 & 0.003 \\
\hline
\end{tabular}

\section{Discussion}

The results of the study showed that among the methods used for reducing and controlling the symptoms of conduct disorder, parent management training had significance impact. Therefore the hypothesis 1was supported.

This finding is in accordance with Kazdin (2005) who reported parent management training is an effective treatment in conduct disorder and with the results of Morch and his colleagues (2005) who reported the impact of this method in treatment of oppositional and conduct disorders. Also, it was observed that elective training is an effective method in treatment of conduct disorder. This is also in line with Kazdin (1996) who reported that PSST plus PMT are effective and long - lasting treatments for antisocial behaviors in children. The findings of this study showed that parental education, especially during childhood have significant impact on the prevention and treatment of conduct disorder, because by growing older and the emergence of adolescence, the effects of parent management training decreases and this effect becomes more effective when it is combined with the training their children problem-solving skills. Previous research has shown a significant difference between problem solving skills training and control group in treatment of conduct disorder (Hains \& Hains, 1988; Wells, 2001; Hawley \& Weisz, 2002; Weisz, Doss, \& Hawley, 2005). Contrary to expectations, the findings showed that problem solving skills training had no effect on reduction of child conduct disorder symptoms in isolation. Therefore hypothesis 2 was not supported. Perhaps one of the reasons why problem solving skills training is not as effective as the other two interventions is that the older children (from around 12) can sufficiently think abstractly. They can be taught the problem-solving process directly, by using real-life examples and 'live applications' to illustrate the process, but younger children will learn best by having the process demonstrated repeatedly by adults to help them solve their day-to-day social and other problems. As mentioned earlier, conduct disorder is an externalize disorder that the parents and caregivers should be taught how to deal with children. The results showed that the most important factor in reducing and controlling the symptoms of conduct disorder is family training. It is hypothesized that the eclectic training decreases the conduct disorder symptoms. The results confirmed the hypothesis 3 , showing that the eclectic training decreases the conduct disorder symptoms.

Despite the limitations of the study such as male students, small sample size, early-onset type CD, these findings suggest that parent management training combined with problem-solving skills training are effective in decreasing children behavioral problems. These findings are important for the clinical field because they show that PMT and PSST together are the robust interventions suitable for behavioral problems, especially conduct disorder.

\section{Acknowledgements}

I gratefully acknowledge the help of the students, mothers, fathers, teachers and school staff who participated in the study without whom this research would not possible. I also like to thank the assistance of Isfahan Education Organization and Psychological Services and Counseling Center of Isfahan Education. 


\section{References}

Achenbach, T. M. (1991). Manual for the Child Behavior Checklist/4-18 and 1991 Profile. Burlington: University of Vermont, Department of Psychiatry.

American Psychiatric Association. (2003). Diagnostic and statistical manual of mental disorders (4th ed.). Washington, DC: Author.

Briesmeister. J. M., \& Schaefer. C. E. (2007). Handbook of Parent Training. Helping Parents Prevent and Solve Problem Behaviors. New Jersey: John Wiley \& Sons.

Cohen, J. A. (1960). A coefficient for agreement of nominal scales. Educational and Psychological Measurement, 20, 37-46. http://dx.doi.org/10.1177/001316446002000104

Domino, G., \& Domino, Marla. L. (2006). Psychological testing (2nd ed.). An introduction: Cambridge University Press.

Frick, P. J., \& Dickens, C. (2006). Current perspectives on conduct disorder. Current Psychiatry Reports, 8, 59-72. http://dx.doi.org/10.1007/s11920-006-0082-3

Frick, P. J. (1998b). Conduct disorders and severe antisocial behavior. New York: Plenum Press.

Frick, P. J. (2001). Effective interventions for children and adolescents with conduct disorder. Canadian Journal of Psychiatry, 46, 597-608.

Hains, A. A., \& Hains, A. H. (1988). Cognitive-behavioral training of problem-solving and impulse-control with delinquent adolescents. Journal of Offender Counseling, Services and Rehabilitation, 12, 95-113. http://dx.doi.org/10.1300/J264v12n02_07

Hawkins, J. D., Herrenkohl, Farrington, D. P., Brewer, D., Catalano, R. F., \& Harachi, T. W. (1998). A review of predictors of youth violence. In Serious\&violent juvenile offenders: Risk factors and successful interventions, edited by R. Loeber and D. P. Farrington. Thousand Oaks, CA: Sage.

Hawley, K. M., \& Weisz, J. R. (2002). Increasing the relevance of evidence-based treatment review to practitioners and consumers. Clinical Psychology: Science and Practice, 9(2), 225-230. http://dx.doi.org/10.1093/clipsy.9.2.225

Kazdin, A. E. (1995). Conduct Disorders in Childhood and Adolescence (2nd ed.). Thousand Oaks, CA: Sage.

Kazdin, A. E. (1997). Parent management training: Evidence, outcomes, and issues. Journal of the American Academy of Child and Adolescent Psychiatry, 36, 1349-1356. http://dx.doi.org/10.1097/00004583-199710000-00016

Kazdin, A. E. (2001). Treatment of conduct disorders. In J. Hill \& B. Maughan (Eds.), Conduct disorders in childhood and adolescence (pp. 408-448). Cambridge, UK: Cambridge University Press.

Kazdin, A. E. (2003). Problem-solving skills training and parent management training for conduct disorder. In A. E. Kazdin \& J. R. Weisz (Eds.), Evidenced-based psychotherapies for children and adolescents (pp. 241-262). New York: Guilford Press.

Kazdin, A. E., Esveldt-Dawson, K., French, N. H., \& Unis, A. S. (1987). Problemsolving skills training and relationship therapy in the treatment of antisocial child behavior. Journal of Consulting and Clinical Psychology, 55, 76-8. http://dx.doi.org/10.1037/0022-006X.55.1.76

Kazdin, A. E. (1998). Psychosocial treatments for conduct disorder in children. In P. E. Nathan \& J. M. Gorman (eds) A guide to treatments that work (pp. 65-89). New York: Oxford University Press.

Kazdin, A. E. (1996). Problem-solving and parent management in treating aggressive and anti-social behavior. In E. D. Hibbs \& P. S. Jensen (Eds.), Psychosocial treatments for child and adolescent disorders: Empiricallybased strategies for clinical practice (pp. 377-408). Washington, DC: American Psychological Association.

Kazdin, A. E. (2005). Parent management training: Treatment of oppositional, aggressive, and antisocial behavior in children and adolescents. New York: Oxford University Press.

Lahey B. B, Moffitt T. E., \& Caspi A. (2003). Causes of conduct disorder and juvenile delinquency. New York (NY): Guilford Press.

Lahey, B. B., Miller, T. L., Gordon, R. A., \& Riley, A. W. (1999). Developmental epidemiology of the disruptive behavior disorders. In H. C. Quay \& A. E. Hogan (Eds.), Handbook of disruptive behavior disorders (pp. 
23-48). New York: Kluwer/Plenum.

Mabe, P. A. (2003). Parent management training and the treatment of conduct disorder. Journal of Forensic Psychology Practice, 3, 61-72.

McMahon, R. J., \& Wells, K. C. (1998). Conduct problems. In E. J. Mash \& R.A. Barkley (Eds.), Treatment of childhood disorders (2nd ed.). (pp. 111-207). New York: Guilford Press.

Moffitt, T. E. (1993)"Life-course-persistent 'and "adolescence-limited" antisocial behavior: a developmental taxonomy. Psychological review, 100, 674-701. http://dx.doi.org/10.1037/0033-295X.100.4.674

Morch, W. T., Clifford, G., Larsson, B., Rypdal. P., Drugli, M. B., \& Fossum, S. (2005). Treatment of oppositional and conduct disorders in 4-8 Year old children using child therapy and/or parent management training. Manuscript in preparation.

Nock, M. K., Ferriter, C., \& Holmberg, E. (2007). Parent Beliefs about Treatment Credibility and Effectiveness: Assessment and Relation to Subsequent Treatment Participation. Journal of Child Fam Stud, 16, 27-38. http://dx.doi.org/10.1007/s10826-006-9064-7

Ollendick, T. H., \& King, N. J. (2000). Empirically supported treatments for children and adolescents. New York: Guilford Press.

Oltmanns ,T. F., \& Emery, R. E. (2012). Abnormal psychology. (3nd ed.). Pearson Education, Inc.

Sanders, M. R., Bor, W., \& Morawska, A .(2007). Maintenance of treatment gains: a comparison of enhanced, standard, and self-directed triple P-positive parenting program. Journal of Abnormal Child Psychology, 35, 983-998. http://dx.doi.org/10.1007/s10802-007-9148-x

Scheepers, F. E., Buitelaar. J. K., \& Matthys. W. (2011). Conduct Disorder and the specifier callous and unemotional traits in the DSM-5. Healing addiction. Eur Child Adolesc Psychiatry, 20, 89-93. http://dx.doi.org/10.1007/s00787-010-0149-x

Schroeder, C. S., \& Gordon, B. N. (2002). Assessment and treatment of childhood problem a Clinician's Guide. New York: Guilford press.

Weisz, J. R., Doss, A. J., \& Hawley, K. M. (2005). Youth psychotherapy outcome research: A review and critique of the evidence base. Annual Review of Psychology, 56, 337-363. http://dx.doi.org/10.1146/annurev.psych.55.090902.141449

Wells, C. (2001). The treatment of severe antisocial behaviour in young people. In G. Baruch(ed.), Community-based psychotherapy with young people: Evidence and innovation in practice. Philadelphia, PA: Brunner-Routledge. 